\title{
A COMPARATIVE STUDY BETWEEN 3-D PLATES AND CONVENTIONAL MINIPLATES FOR INTERNAL FIXATION OF ANTERIOR MANDIBULAR FRACTURES
}

\author{
Norhan A. El Nakeeb ${ }^{l}$, Mostafa M. El Dibany', Mohamed M. Shokry ${ }^{3}$
}

\begin{abstract}
INTRODUCTION: The management of facial trauma is one of the most demanding aspects of oral and maxillofacial surgery. Being the most prominent mobile bone of the facial skeleton, mandible fracture occurs more frequently than any other facial fracture.

OBJECTIVES: To compare between the effect of three dimensional (3D) plates and conventional miniplates for internal fixation of anterior mandibular fractures.

MATERIALS AND METHODS: This was a controlled and randomized clinical trial. A total of 20 patients; aged between 21-50 years, who had symphyseal or parasymphseal mandibular fracture were randomly selected for this study from the outpatient clinic of Oral and Maxillofacial Surgery Department, Faculty of dentistry, Alexandria University. In this study, open reduction and internal fixation were performed for mandibular symphyseal and parasymphyseal region fractures using one three dimensional (3D) plate in 10 patients as study group and using two miniplates in 10 patients as control group. Clinical and radiographical evaluation were made. Each patient was evaluated: 1- clinically for infection, pain, swelling, malocclusion, wound healing, sensory disturbance, primary stability of the fracture segment, maximum mouth opening and masticatory efficiency using pressure indicating film. 2-Radiological: cone beam computed tomography (CBCT) images were taken to evaluate reduction of the fractured segment, malunion/non-union and bone density within the fracture line. The data collected was subjected to statistical analysis.

RESULTS: There was an improvement in wound healing, oedema, occlusion and sensory disturbance in both groups. There was no statistical significant difference between the two groups regarding pain, maximum mouth opening, bite force or bone density.

CONCLUSIONS: Three dimensional plate is effective in the treatment of anterior mandibular fractures as well as conventional miniplates. Ease of application and shorter working time are its advantages over conventional miniplates.

KEY WORDS: 3D plate, Miniplates, Symphyseal, Parasymphyseal, mandibular fracture.

1- B.D.S. Faculty of Dentistry, Alexandria University, Alexandria, Egypt

2- Professor of Oral \& Maxillofacial Surgery, Faculty of Dentistry, Alexandria University, Alexandria, Egypt

3- Oral Surgical Sciences Department, Faculty of Dentistry, Beirut Arab University \& Lecturer of Oral \& Maxillofacial Surgery, Faculty of Dentistry, Alexandria University, Alexandria, Egypt
\end{abstract}

\section{INTRODUCTION}

Due to the prominent position and configuration of the mandible, it is one of the most frequent facial bones to be fractured (1). Because of the mandible's contribution to speech, mastication, deglutition and to the form of the lower portion of the face, fractures of this structure must receive careful consideration (2). Successful treatment of mandibular fractures results in an anatomic bony union with restoration of normal occlusion and function $(1,2)$.

The most common causes of mandibular fractures are road traffic accidents, falls, gunshot injuries, interpersonal violence and sporting accidents $(3,4)$.

Reduction and immobilization is the accepted universal principle to treat a bony fracture and this goal can be achieved with a variety of treatment modalities (5). In simple terms, treatment may be categorized as closed reduction plus intermaxillary fixation or open reduction with internal fixation (ORIF). Open reduction with internal fixation may be accomplished with transosseous wires or with bone plates \& screws, performed intraorally or extraorally (5).

Previously the most popular method for mandibular fracture treatment was closed reduction plus intermaxillary fixation and open reduction with internal fixation with wire osteosynthesis, necessitating an average of 6 weeks of IMF for satisfactory healing. This long period of IMF causes bad oral hygiene, increase the caries incidence and difficulty in speech and mastication (6).
However, open reduction and internal fixation is the preferred treatment method of mandibular fractures but at the same time it is very expensive and needs an experienced surgeon to get the optimum results (6).

Small size of the plate, easy adaptability, easy placement and use of intraoral approach led to increased use of monocortical plates in maxillofacial surgery (7).

However, it is advocated that miniplates did not offer adequate stabilization of the fractures (8), thereby necessitating the need of further inter-maxillary fixation. Farmand and Dupoirieux (9) presented 3-D plates with quadrangular shape formed by joining two miniplates with interconnecting crossbars. Because of the quadrangular configuration of the plates, they provided good stability and resistance to torsional forces. Easy use, good resistance against torque forces, and compact form of the plates were some of these advantages $(8,9)$.

The purpose of this study was to compare the outcomes of treatment and postoperative complications using either 3-D plates versus conventional $2.0 \mathrm{~mm}$ miniplates, in patients who had sustained a fracture in the mandibular symphyseal or parasymphyseal region.

\section{MATERIALS AND METHODS Study design}

This study was carried out as a randomized controlled clinical trial. 


\section{Selection of patients}

This study was conducted on 20 patients who were selected, and operated in the Oral and Maxillofacial surgery department, Faculty of Dentistry, Alexandria University, Egypt. Appropriate ethical clearance was obtained from the ethical committee of the university. Each patient had been informed about the nature of this study and gave an informed consent.

Twenty patients with symphyseal or parasymphyseal mandibular fracture were included in this study. The twenty patients were selected conveniently to fulfil the following inclusion and exclusion criteria.

The 20 patients were divided randomly into two equal groups:

Group A: (Study group), where anterior mandibular fractures were fixed using one $3 \mathrm{~d}$ plate.

Group B: (Control group), where anterior mandibular fractures were fixed using two conventional miniplates.

\section{Inclusion Criteria of selection}

Patient's age ranges from 21-50 years, of both gender and they should have unfavourable symphyseal or unfavourable unilateral parasymphyseal mandibular fracture.

\section{Exclusion criteria of selection}

Patients with bone diseases affecting bone healing, patients contraindicated to general anesthesia, patients presenting with infection at the fracture site and patients not willing to return for follow up.

\section{Materials}

-Rectangular titanium 3D miniplate $(4 \times 2$ holes interconnected by vertical struts) (Jeil Medical Corporation, Guro-gu, Seoul, Korea) of $1.0 \mathrm{~mm}$ thickness secured with titanium monocortical screws of $2.0 \mathrm{~mm}$ head diameter. -Conventional $2.0 \mathrm{~mm}$ miniplates (Jeil Medical Corporation, Guro-gu, Seoul, Korea). 4 or 5-hole titanium miniplates of $1.0 \mathrm{~mm}$ thickness and secured with titanium monocortical screws of $2.0 \mathrm{~mm}$ head diameter.

\section{Methods}

\section{1- Preoperative phase}

\section{A- History of the patient}

Basic personal data were adequately taken together with the history of the trauma and Past medical history as well as drug history.

\section{B- Clinical examination}

1- Extraoral and intraoral examination through inspection and palpation was done involving detection of malocclusion and nerve disturbance.

\section{2- Measuring of mouth opening}

By using calipers (Shanghai Afimao Dental Industries Co., Ltd) to measure maximum interincisal mouth opening between upper central incisor and lower central incisor.

\section{3- Measuring of bite force}

- Using pressure indicating film (Pressurex ${ }^{\circledR}$, Sensor Products INC, New Jersey, USA).

- The pressure indicating film is an easy and unique tool to use that reveals the distribution and magnitude of the force between any two contacting surfaces.

- The pressure indicating film is a Mylar based film that contains a layer of tiny microcapsules. The application of force upon the film causes the microcapsules to rupture, producing an instantaneous and permanent high resolution "topographical" image of pressure variation across the contact area (10-12).

- The pressure indicating films used in measuring the bite force is the two-sheet type which is used to measure force range from $2 \mathrm{~kg}$ to $100 \mathrm{~kg}$. It is composed of two polyester bases, one is coated with a layer of microencapsulated color forming material and the other is a layer of the color-developing material.

- The film is cut to the precise dimension to measure the bite force. Both sheets donor and receiver sheets were cut to the same exact shape. The two rough surfaces were placed together before applying force. By placing these two surfaces together, the color forming material on the donor sheet react with the color developing material on the receiver sheet.

- All measurements were done while the patients were seated with the head upright, looking forward and in an unsupported natural position.

- The patients were instructed to bite on a Pressure indicating film to a maximum level by biting as forcefully as possible for 5 seconds on both sides.

- Instantly and permanently, the film was turned to a magenta color where the intensity was directly proportional to the amount of force.

- In order to determine the force applied across the pressure indicating film, the following steps were followed:

The processed pressure indicating films and color calibration swatch were scanned.

- Photoshop CS4 program was used to get the color density on the film and correlate it with the color swatch to determine the amount of pressure applied over the film.

- The force was measured by matching the number of pixels to a known surface area, then determined as: Force $=$ Pressure $\times$ Surface area.

\section{C- Radiographic examination}

Standard Orthopantomogram (OPG) of the mandible was taken for all patients at the time of presentation to evaluate the condition of the mandibular fracture, teeth in the line of fracture, degree of displacement and to assess the available space to compensate the $3 \mathrm{D}$ plate in relation to the tooth apices and the mental nerve.

\section{2- Operative phase}

All operations were performed under general anaesthesia within the theatres of Oral and Maxillofacial Surgery Department, Faculty of Dentistry, Alexandria University. Patient received induction and muscle relaxant then intubated via cuffed naso-tracheal tube.

- A pack was applied to prevent any blood, saline and foreign bodies to fall in the airway.

- Patient was put in a hyper-extended neck position after ensuring that patient did not have a cervical spine fractures.

- The oral cavity was washed with Betadine (Povidoneiodine, $7.5 \%$ ( $0.75 \%$ available iodine), The Nile Co.for Pharmacueticals and Chemical Industries) then all around the extra-oral surgical site followed by draping the sterile towels.

- Management of teeth in the fracture line was done through extraction or preservation according to the preoperative assessment.

- Ivy loops or arch bars were fixed to the present teeth.

- Maxillomandibular fixation (MMF) was established to line up the teeth in normal occlusion.

- Access to the fracture site was generally obtained through an intraoral approach. 
- Exposure of the fracture site was obtained by a standard layered dissection through mucosa, Mentalis muscle and the periosteum. The mucoperiosteal flap was raised carefully keeping the mental neurovascular bundle intact.

- Debridement of the fracture was done.

- Fragments were reduced and held in position and confirmed visually by verifying the alignment of the buccal cortex and inferior border. The segments were manipulated with bone clamps and satisfactorily reduced.

- For group A: patients, one 3-D plate was contoured, applied and fixed using monocortical screws (Figure 5a).

- For group B: patients, two conventional $2.0 \mathrm{~mm}$ miniplates were contoured, applied and fixed using monocortical screws (Figure 5b).

Steps of plate fixation

1- The plate was properly adapted to fit passively over the fracture with slight over bending (1-2 mm).

2- Holding the plate at its proper place in subapical position of teeth.

3- Monocortical eccentric drilling of the two holes closest to the line of fracture was done with appropriate sized drill under constant saline irrigation.

4- The first screw was driven to hold the plate in position but not completely tightened.

5- The second screw was tightened completely and then tightening the first one completely.

6- Monocortical centric drilling of the additional plate holes under constant saline irrigation and tightening of the additional screws was done.

- The incision was closed in layers using Vicryl suture material (Vicryl: resorabble suture material by Johnson Int., C/O European Logistics Centre, Lenneke Marelaa 6, BE1932 ST-Stevens- Wolume, Belgium).

- Upon completion of the procedure, MMF was released and occlusion was verified.

3- Postoperative phase

- All patients were instructed to take:

1- Antibiotic (Amoxicillin \& clavulanate Potassium orally 1 gm twice daily) (Augmentin $1 \mathrm{~g}$ manufactured by GlaxoSmithKline).

2- Analgesic (Diclofenac Potassium orally $50 \mathrm{mg}$ twice daily) Cataflam (50 mg) Manufactured by (Novartis (Swiss multinational pharmaceutical company).

3- Anti-edematous ( $\alpha$-Chymotrypsin ampoules IM once daily) $\alpha$ - chymotrypsin ampoules (Chymotrypsin 450 E.A. $\mathrm{U}=5 \mathrm{mg}$, Manufactured by Amoun (Egyptian pharmaceutical company).

- The patients were instructed to perform cold fomentations for the first 24 hours to be replaced by warm fomentations for four days and perform oral hygiene measures, stop smoking, avoid biting on any hard food and rest.

\section{4- Follow up and criteria of evaluation}

Clinical evaluation

\section{Postoperative healing}

Healing was evaluated clinically on the second day, after the first week and after the second week postoperatively for soft tissue dehiscence, oedema, bleeding, inflammation or infection.

\section{Occlusion}

Occlusion was checked along the follow up period in the maximal intercuspal position to ensure proper occlusal relationship including molar relation and midline centralization.

\section{Sensory function}

Assessment of sensory function along the follow up period subjectively by asking the patient about any alteration in sensation in addition to objective examination by using a dental probe to assess the sensory changes along the distribution of the mental nerve (lower lip and chin) through examining lip sensation in comparison to the contralateral side (13).

\section{Postoperative pain}

Pain was evaluated on the second day, after the first week and after the second week postoperatively through visual analogue scale (14) as follows:

$0=$ No pain.

$1=$ Mild pain: It is easily tolerated.

$2=$ Moderate pain: It is causing discomfort but bearable.

$3=$ Severe pain: It is causing discomfort, hardly tolerated and unbearable.

\section{Maximum mouth opening}

All patients were evaluated for maximum interincisal opening in mm using mouth caliper (15) on the second day, after the first week, after the second week, after 6 weeks and after 3 months postoperatively. The measurements were compared to that before the surgery.

\section{Bite force recovery}

Bite force recovery was evaluated on the second day, after the first week, after the second week, after 6 weeks and after 3 months postoperatively through the pressure indicating film. The measurements were compared to that before the surgery.

\section{(B) Radiographic evaluation}

- Panoramic x-ray was done during the first week postoperatively to evaluate reduction \& fixation of the fractured segment.

- Cone beam CT (CBCT) image was taken after 6 weeks and after 3 months to evaluate the fracture healing and the mean bone density.

\section{Measuring bone density}

Bone density was calculated from the cross-Sectional cut using Hounsfield unit through ROI (region of interest) within the cone beam software (On Demand3DAPP-DBM) by selecting a $100 \times 250$ rectangle placed every time at the site of the fracture line.

\section{STATISTICAL ANALYSIS OF THE DATA (16)}

Data were fed to the computer and analyzed using IBM SPSS software package version 20.0. (17). Qualitative data were described using number and percent. Quantitative data were described using range (minimum and maximum), mean, standard deviation and median. Significance of the obtained results was judged at the $5 \%$ level.

\section{RESULTS}

The current study has been conducted on twenty patients selected from those admitted to the Oral and Maxillofacial Surgery Department, Faculty of Dentistry, Alexandria University suffering from mandibular symphyseal or parasymphyseal fracture. 
The patients were divided into two groups each consisting of ten patients. Their age ranged from 21-50 years old with a mean of 33.15 years. Incidence in males compared with that of females was $4: 1$.

The cause of the trauma was road traffic accidents in fifteen patients (ten of them were hit by motorcycle), assaults in two patients, falls in two patients and work related fracture in one patient.

\section{Study group (Group A)}

Included ten patients; seven males and three females. Their age ranged from 21-50 years with a mean of 33.60 years. Nine patients had parasymphyseal fracture and one patient had symphyseal fracture. Five patients had the parasymphyseal fracture on the right side and four patients had left parasymphyseal fracture. Two cases only had a traumatized non-vital tooth in the fracture line which preserved with postoperative root canal treatment. All fractures were fixed with 3D plates. The time taken from the $3 \mathrm{D}$ plate adaptation to the definitive fixation ranged from 5 to 10 minutes.

\section{Control group (Group B)}

Included ten patients; nine males and one female. Their age ranged from 21-48 years with a mean of 32.70 years. Eight patients had parasymphyseal fracture and two patients had symphyseal fracture. Two patients had the parasymphyseal fracture on the right side and six patients had left parasymphyseal fracture. One case only had a traumatized tooth in the fracture line which managed with extraction during the operation to prevent interference with reduction. All fractures were fixed with conventional miniplates. The time taken from the miniplate adaptation to the definitive fixation ranged from 10-15 minutes.

\section{Clinical findings}

\section{Postoperative clinical findings}

- As regards wound healing, no postoperative soft tissue dehiscence, bleeding, inflammation or infection was detected except one patient $(10 \%)$ in group (B) developed infection, which was managed with another course of antibiotic and was totally resolved.

- Furthermore, oedema was limited only to the area adjacent to the fracture site and resolved after one week.

- Moreover, occlusion was satisfactory along the follow up period in both groups (Figures 1 \& 2).

- Finally, no sensory impairment was reported except two cases in each group presented with lower lip numbness, but all showed gradual improvement till the third month postoperatively where normal sensation was restored.

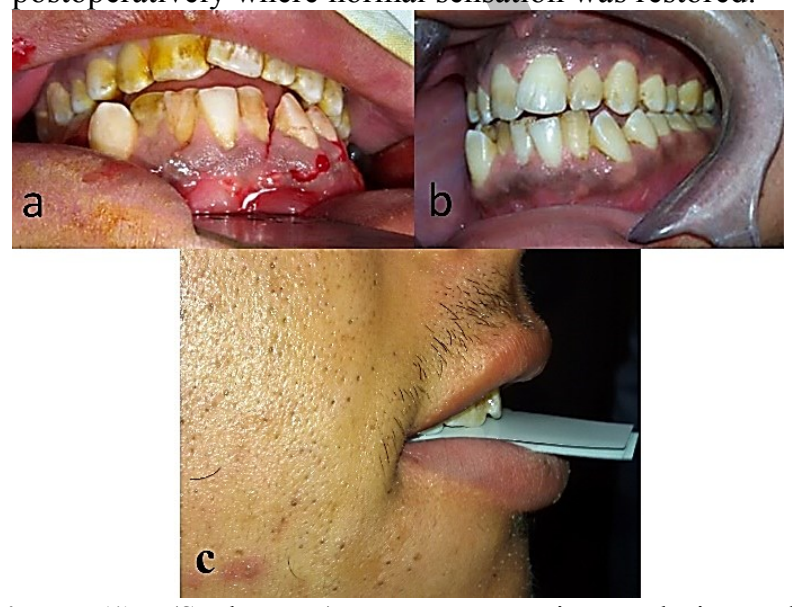

Figure (1): (Study case): a. Preoperative occlusion. b Postoperative occlusion. c. Measuring the bite force using the pressure indicating film.

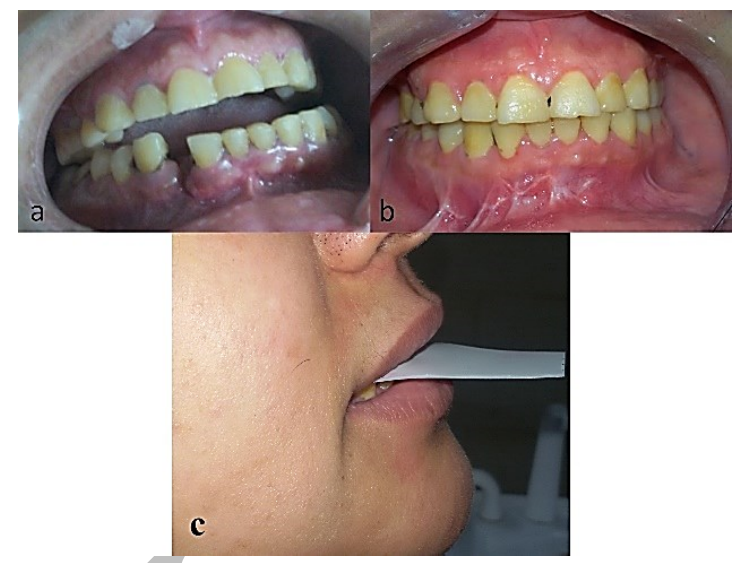

Figure (2): (Control case): a. Preoperative occlusion. b. Postoperative occlusion. c. Measuring the bite force using the pressure indicating film.

\section{Pain}

On the second day postoperatively, the mean pain score for group A was 2.5 while for group B was 2.70, after the first week postoperatively, the mean pain score for group A was 1.60 while for group B was 1.90 and after the second week postoperatively, it was 0.80 for group A while for group B it was 0.90 .

And so, there was no statistically significant difference between the two groups regarding the mean pain score on the second day, after the first week and after the second week postoperatively and pain was significantly decreased in all cases in both groups across the follow up period (Table $1)$.

\section{Maximum mouth opening}

Preoperatively, the mean maximum mouth opening for group A was 21.80 while for group B was 20.11, on the second day postoperatively, the mean maximum mouth opening for group A was 30.62 while for group B was 24.03 , after the first week postoperatively, the mean maximum mouth opening for group A was 38.28 while for group B was 30.37 , after the second week postoperatively, the mean maximum mouth opening for group A was 41.55 while for group B was 37.25, after six weeks postoperatively, the mean maximum mouth opening for group A was 44.05 while for group B was 39.04 and after 3 months postoperatively, it was 47.97 for group A while for group B it was 41.11.

And so, there was no statistically significant difference between the two groups regarding maximum mouth opening preoperatively, on the second day, after the first week, after the second week, after 6 weeks and after 3 months postoperatively and maximum mouth opening was significantly increased in all cases in both groups across the follow up period.

\section{Postoperative bite force recovery}

Preoperatively, the mean bite force in group A was 169.95 $\mathrm{N}$ while in group $\mathrm{B}$ was $213.36 \mathrm{~N}$, on the second day postoperatively, the mean bite force in group A was 206.93 $\mathrm{N}$ while in group $\mathrm{B}$ was $231.99 \mathrm{~N}$, after the first week postoperatively, the mean bite force in group A was 234.58 $\mathrm{N}$ while in group B was $246.06 \mathrm{~N}$, after the second week postoperatively, the mean bite force in group A was 261.93 $\mathrm{N}$ while in group $\mathrm{B}$ was $265.26 \mathrm{~N}$, after six weeks postoperatively, the mean bite force in group A was 291.27 $\mathrm{N}$ while in group $\mathrm{B}$ was $296.03 \mathrm{~N}$ and after 3 months postoperatively, it was $315.28 \mathrm{~N}$ for group A while in group $\mathrm{B}$ it was $333.79 \mathrm{~N}$. 
And so, there was no statistically significant difference between the two groups regarding bite force preoperatively, on the second day, after the first week, after the second week, after 6 weeks and after 3 months postoperatively and bite force was significantly increased in all cases in both groups across the follow up period (Table 2).

Table 1: Comparison between the two studied groups according to pain.

\begin{tabular}{|c|c|c|c|c|c|c|}
\hline & \multicolumn{6}{|c|}{ Pain } \\
\hline & \multicolumn{2}{|c|}{ Second day } & \multicolumn{2}{|c|}{ First week } & \multicolumn{2}{|c|}{ Second week } \\
\hline & No & $\%$ & No & $\%$ & No & $\%$ \\
\hline $\begin{array}{l}\text { Group A (n } \\
=10)\end{array}$ & & & & & & \\
\hline $0=$ No pain & 0 & 0.0 & 2 & 20.0 & 4 & 40.0 \\
\hline $1=$ Mild pain & 1 & 10.0 & 2 & 20.0 & 4 & 40.0 \\
\hline $\begin{array}{l}2=\text { Moderate } \\
\text { pain }\end{array}$ & 3 & 30.0 & 4 & 40.0 & 2 & 20.0 \\
\hline $\begin{array}{l}3=\text { Severe } \\
\text { pain }\end{array}$ & 6 & 60.0 & 2 & 20.0 & 0 & 0.0 \\
\hline $\begin{array}{l}\text { Min. - Max. } \\
\text { Mean } \pm \text { SD } \\
\text { Median }\end{array}$ & & $\begin{array}{l}3.0 \\
0.71 \\
0 \\
\end{array}$ & $\begin{array}{r}0.0 \\
1.60 \\
\end{array}$ & $\begin{array}{l}-3.0 \\
=1.07 \\
0 \\
\end{array}$ & \multicolumn{2}{|c|}{$\begin{array}{c}0.0-2.0 \\
0.80 \pm 0.79 \\
1.0 \\
\end{array}$} \\
\hline $\begin{array}{l}\text { Sig. bet. } \\
\text { periods }\end{array}$ & \multicolumn{6}{|c|}{$\mathrm{p}_{1}=0.014^{*}, \mathrm{p}_{2}=0.004^{*}, \mathrm{p}_{3}=0.005^{*}$} \\
\hline \multirow{5}{*}{$\begin{array}{l}\text { Group B (n } \\
=\mathbf{1 0}) \\
0=\text { No pain } \\
1=\text { Mild pain } \\
2=\text { Moderate } \\
\text { pain } \\
3=\text { Severe } \\
\text { pain }\end{array}$} & & & & & & \\
\hline & 0 & 0.0 & 1 & 10.0 & 4 & 40.0 \\
\hline & 0 & 0.0 & 1 & 10.0 & & 40.0 \\
\hline & 3 & 30.0 & 6 & 60.0 & & 10.0 \\
\hline & 7 & 70.0 & 2 & 20.0 & 1 & 10.0 \\
\hline $\begin{array}{l}\text { Min. - Max. } \\
\text { Mean } \pm \text { SD } \\
\text { Median }\end{array}$ & $\begin{array}{r}2 . \\
2.7\end{array}$ & $\begin{array}{l}3.0 \\
0.48 \\
0 \\
\end{array}$ & $\begin{array}{r}0.0 \\
1.90\end{array}$ & $\begin{aligned} &-3.0 \\
&= 0.88 \\
& 0 \\
&\end{aligned}$ & $\begin{array}{r}0.0- \\
0.90 \pm \\
1 .\end{array}$ & \\
\hline $\begin{array}{l}\text { Sig. bet. } \\
\text { Periods }\end{array}$ & \multicolumn{6}{|c|}{$\mathrm{p}_{1}=0.011^{*}, \mathrm{p}_{2}=0.007^{*}, \mathrm{p}_{3}=0.008^{*}$} \\
\hline $\mathrm{Z}$ & \multicolumn{2}{|c|}{0.587} & \multicolumn{2}{|c|}{0.651} & \multicolumn{2}{|c|}{0.081} \\
\hline $\mathbf{P}$ & \multicolumn{2}{|c|}{0.557} & \multicolumn{2}{|c|}{0.515} & \multicolumn{2}{|c|}{0.935} \\
\hline
\end{tabular}

Z: Z for Mann Whitney test

Sig. bet. periods were done using Wilcoxon signed ranks test $\mathrm{p}_{1}$ : $\mathrm{p}$ value for comparing between Second day and First week $\mathrm{p}_{2}$ : $\mathrm{p}$ value for comparing between Second day and Second week $\mathrm{p}_{3}$ : $\mathrm{p}$ value for comparing between First week and Second week $*$ : Statistically significant at $\mathrm{p} \leq 0.05$

\section{Radiographic findings}

Both groups showed good reduction and fixation in all cases with alignment of the osseous borders of the mandible (Figures $3 \& 4$ ).

\section{Bone density measurement}

After six weeks postoperatively, the mean bone density for group A was 727.84 while for group B was 943.10 while after 3 months postoperatively, it was 1001.57 for group A while for group B it was 1126.71.

And so, there was no statistically significant difference between the two groups regarding bone density after 6 weeks and after three months postoperatively and bone density was significantly increased in all cases in both groups across the follow up period (Table 3, Figure 6).

\section{DISCUSSION}

In the current study, twenty patients were selected with anterior mandibular fracture (Symphyseal or Parasymphyseal). The first group in this study included ten patients in whom mandibular fracture was reduced and fixed by single 3D plate. The second group included ten patients in whom mandibular fracture was reduced and fixed by two conventional miniplates. In both groups the fracture site was exposed using an intraoral approach according to Champy et al (18).

Table 2: Comparison between the two studied groups according to bite force.

\begin{tabular}{|c|c|c|c|c|c|c|}
\hline & \multicolumn{6}{|c|}{ Bite force } \\
\hline & $\begin{array}{c}\text { Pre- } \\
\text { operative }\end{array}$ & $\begin{array}{c}\text { Second } \\
\text { day }\end{array}$ & $\begin{array}{l}\text { First } \\
\text { week }\end{array}$ & $\begin{array}{c}\begin{array}{c}\text { Second } \\
\text { week }\end{array} \\
\end{array}$ & 6 weeks & 3 Months \\
\hline $\begin{array}{c}\text { Group A } \\
(n=10)\end{array}$ & & & & & & \\
\hline $\begin{array}{l}\text { Min. - } \\
\text { Max. }\end{array}$ & $\begin{array}{c}127.25- \\
267.0\end{array}$ & $\begin{array}{c}135.05- \\
277.67\end{array}$ & $\begin{array}{l}137.9- \\
338.10\end{array}$ & $\begin{array}{l}140.6- \\
440.10\end{array}$ & $\begin{array}{c}156.60- \\
556.0\end{array}$ & $\begin{array}{c}174.80- \\
609.0\end{array}$ \\
\hline Mean \pm & $169.95 \pm$ & $206.93 \pm 4$ & $234.58 \pm 5$ & $261.93 \pm 94$. & $291.27 \pm 117$ & $315.28 \pm 124$ \\
\hline SD & 42.92 & 7.02 & 6.78 & 09 & .13 & .18 \\
\hline Median & 155.69 & 201.02 & 219.30 & 227.0 & 238.80 & 293.10 \\
\hline $\begin{array}{l}\text { Sig. bet. } \\
\text { periods }\end{array}$ & & $0.005^{*}$ & $0.005^{*}$ & $0.005^{*}$ & $0.005^{*}$ & $0.005^{*}$ \\
\hline $\begin{array}{c}\text { Group B } \\
(n=10)\end{array}$ & & & & & & \\
\hline $\begin{array}{l}\text { Min. - } \\
\text { Max. }\end{array}$ & $\begin{array}{c}151.8- \\
315.0\end{array}$ & $\begin{array}{c}179.5- \\
315.0\end{array}$ & $\begin{array}{c}177.6- \\
315.0\end{array}$ & $\begin{array}{c}213.1- \\
339.10\end{array}$ & $\begin{array}{c}239.6- \\
410.96\end{array}$ & $\begin{array}{c}240.10- \\
656.1\end{array}$ \\
\hline Mean \pm & $213.36 \pm 5$ & $231.99 \pm$ & $246.06 \pm 5$ & $265.26 \pm 45$. & $296.03 \pm 53$. & $333.79 \pm 119$ \\
\hline SD & 7.96 & 47.72 & 2.26 & 49 & 22 & .46 \\
\hline Median & 208.94 & 213.55 & 228.25 & 248.80 & 291.04 & 301.0 \\
\hline $\begin{array}{l}\text { Sig. bet. } \\
\text { periods }\end{array}$ & & $0.021^{*}$ & $0.008^{*}$ & $0.047^{*}$ & $0.013^{*}$ & $0.007^{*}$ \\
\hline $\mathbf{Z}$ & 1.890 & 1.058 & 0.529 & 0.983 & 1.286 & 0.756 \\
\hline $\mathbf{P}$ & 0.059 & 0.290 & 0.597 & 0.326 & 0.199 & 0.450 \\
\hline
\end{tabular}

Z: Z for Mann Whitney test

Sig. bet. periods were done using Wilcoxon signed ranks test for comparing between Pre-operative and each other periods

$*$ : Statistically significant at $\mathrm{p} \leq 0.05$

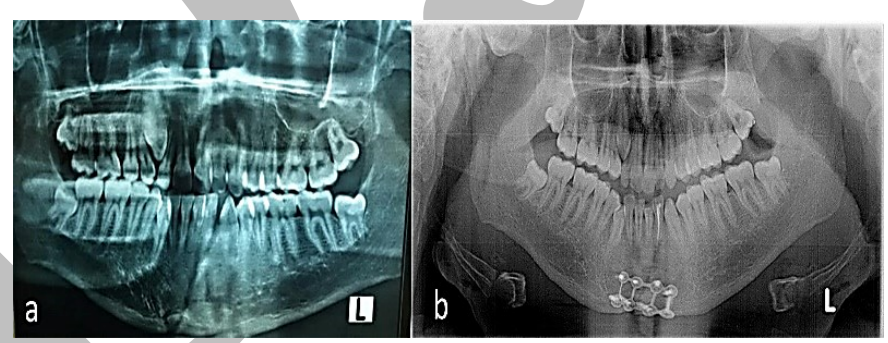

Figure (3): (Study case): a. Preoperative OPG. b. Postoperative OPG.

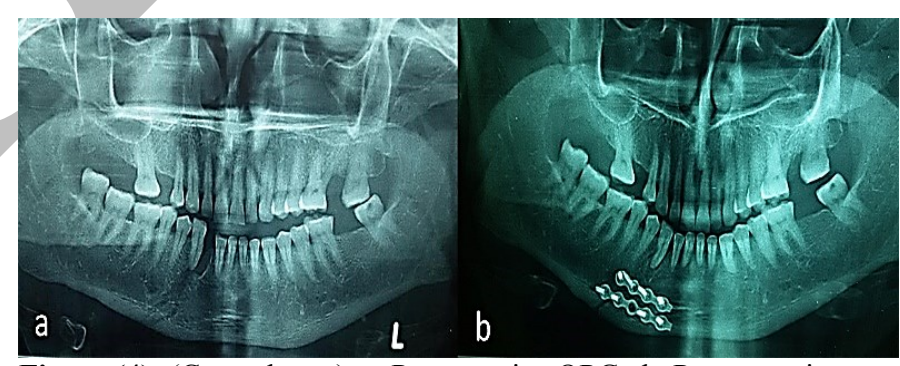

Figure (4): (Control case): a. Preoperative OPG. b. Postoperative OPG.

Table 3: Comparison between the two studied groups according to bone density.

\begin{tabular}{|c|c|c|c|c|}
\hline Bone density & $\begin{array}{c}\text { Group A } \\
(n=10)\end{array}$ & $\begin{array}{c}\text { Group B } \\
(n=10)\end{array}$ & $\mathbf{T}$ & $\mathbf{P}$ \\
\hline $\begin{array}{l}6 \text { weeks } \\
\text { Min. }- \text { Max. } \\
\text { Mean } \pm \text { SD } \\
\text { Median }\end{array}$ & $\begin{array}{c}412.80-1125.20 \\
727.84 \pm 286.28 \\
750.55\end{array}$ & $\begin{array}{c}495.80-1245.0 \\
943.10 \pm 212.10 \\
940.40\end{array}$ & 1.911 & 0.072 \\
\hline $\begin{array}{l}3 \text { months } \\
\text { Min. - Max. } \\
\text { Mean } \pm \text { SD } \\
\text { Median }\end{array}$ & $\begin{array}{c}477.30-1315.50 \\
1001.57 \pm 243.78 \\
1008.40\end{array}$ & $\begin{array}{c}810.0-1289.80 \\
1126.71 \pm 145.13 \\
1141.40\end{array}$ & 1.395 & 0.180 \\
\hline$p_{0}$ & $0.010^{*}$ & $0.001^{*}$ & & \\
\hline
\end{tabular}




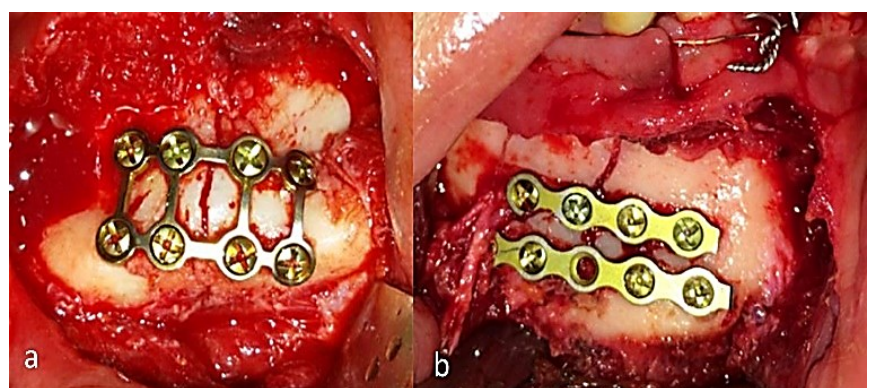

Figure (5): a. Fixation using 3D plate (Study case). b. Fixation using miniplates (Control case).

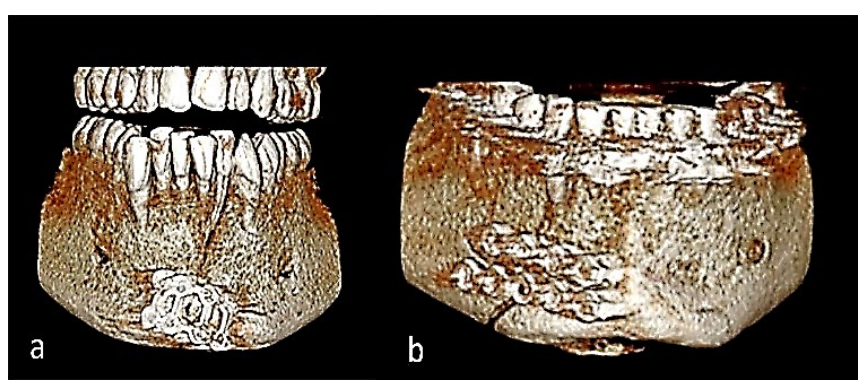

Figure (6): a. CBCT section showing 3D plate in place after 3 months (Study case). b. CBCT section showing miniplates in place after 3 months (Control case).

The age of the patients in this study was in the range of 21-50 years with a mean of 33.15, this is in agreement with Kumar et al (19) who reported an age range of $(19-63)$ with a mean of 33.9 years in their study to compare $3 \mathrm{D}$ plate versus conventional miniplates in the management of mandibular parasymphysis fractures. Also Khalifa et al (20) reported a range of (15-50) with a mean of 32.5 years in their study to compare $3 \mathrm{D}$ plate versus conventional miniplates in fixation of anterior mandibular fractures. It is thought that this result is due to the fact that in our country the young adults present a large mass and are the main mobile segment of population who participate in out-side activities.

In this study, incidence of mandibular fractures in males compared with that of females was (4:1), this is in accordance with Yadav S. et al (21) who reported in their study to evaluate $3 \mathrm{D}$ locking plate that $(90 \%)$ of cases were males and $(10 \%)$ were females. Also Sadhwani and Anchlia (7) reported male dominance in their study to compare conventional miniplates versus $3 \mathrm{D}$ plate in mandibular fractures. The low female incidence in this study could be attributed to the fact that women in our country do not participate in the same physical activities and are less exposed to violence as men and thus are less exposed to trauma.

As regards the etiology of mandibular fractures in this study, road traffics were the main etiologic factor representing $75 \%$ of cases and this is found to be in agreement with Yadav et al (21) who reported that Road traffic accident was the etiological factor in $70 \%$ of cases. Also Sadhwani and Anchlia (7) affirmed that road traffic accidents were responsible for the majority of cases in their study.

3D titanium plates have been used sporadically by few surgeons predominantly for fixation of the mandibular angle region $(22,23)$. Hughes (24) extended its use to the anterior mandible in 2000 . In the current study, all cases had to have anterior mandibular fracture.

The severity of displacement in the mandibular fracture signifies the unfavourability of the fracture and subsequently affects healing outcomes. In the current study, all cases had to have unfavourable anterior mandibular fracture and this is in agreement with Zix et al (25) and Guimond et al (26) who reported $46 \%$ to $80 \%$ of their study subjects to have minimally displaced mandibular fractures.

The time taken from the $3 \mathrm{D}$ plate adaptation to the definitive fixation in this study ranged from 5 to $10 \mathrm{~min}$. It had a faster fixation time compared to the conventional miniplates which had a range of 10-15 min fixation time and this is in agreement with Agrawal et al (27) who reported that the operative time with $3 \mathrm{D}$ plates in the treatment of symphysis and parasymphysis fractures is lesser than conventional miniplates. They suggested that the operative time is shorter because of the simultaneous stabilization at both superior and inferior borders and less implant material is used in symphysis and parasymphysis region. Also, AlMoraissi and Ellis (28) reported that there was significantly shorter operating time with 3-dimensional miniplates over 2 miniplates in the fixation of anterior mandibular fractures. Sadhwani and Anchlia (7) concluded that the only probable limitations of 3D plates were excessive implant material due to the extra vertical bars incorporated for countering the torque forces

In our opinion, the time taken for fixation directly reflects the ease or difficulty in placement of a particular plate. Various surgeons have experienced reduced operating time with the usage of 3D plates. Hughes (24) and Feledy (29) in their clinical studies found better bending stability in 3D plates and stated that, the easier application of 3D plates was reflected in a reduced average operating time. Zix et al (25) commented that because of their simultaneous stabilization at both superior and inferior borders, 3D plates are a time saving alternative to conventional miniplates. This was explained by Jain et al (15) as he stated that a geometric plate is much broader and has to be bent to adapt a "plane" rather than a "line" to a curved surface.

Postoperatively, clinical and radiographic outcomes in this study were evaluated in both groups over a 3-months follow up period and this is in accordance to Kawai et al (30) who suggested in his study on the radiographic changes during bone healing after mandibular fractures that the clinical judgment of whether the fracture healed or not is obtained mostly at this time.

Mandibular fracture fixation has its share of complications in the form of bone and soft tissue infection, malunion, delayed union, non-union, plate fracture and most importantly malocclusion. The studies showed complication rates of miniplate osteosynthesis for mandibular fractures treatment ranged approximately from $3.8 \%$ to $28 \%$ over the last three decades $(18,22,23,25$, $26)$. For $3 \mathrm{D}$ plate fixation in mandibular fractures the complication rates reported so far range from $0 \%$ to $10 \%$ (31-35).

In this study, none of the patients in either of the groups had nonunion, plate fracture, or loosening of plate and screws within the follow up period and this is in agreement with Agrawal et al (27) who reported that no such significant complications were noted in both conventional and 3D miniplates. Also Melek et al (36) reported that in their study of 3D plate in mandibular angle fracture.

In this study, none of the patients in both groups developed infection except one case in group B which was managed with another course of antibiotic and was totally resolved. Also Agrawal et al (27) recorded temporary 
infection in two cases and reported that difference was not statistically significant. Parmar et al (37) reported an infection rate of $6.6 \%$ in the $3 \mathrm{D}$ plate.

The results of the present study had shown that all patients in group A had no postoperative occlusal disturbances due to adequate stabalization of the fractured segments. This is consistent with the literatures of Zix et al (25), Guimond et al (26) and Feledy et al (29) which showed that the occurrence of occlusal changes in $3 \mathrm{D}$ plate ranged from $0 \%$ to $20 \%$. This is most probably attributed to the higher stability of fracture segments and consequently stable occlusion offered by the 3D plate design. Also all patients of group B in this study had no post-operative occlusal disturbance. Sadhwani and Anchlia (7) reported one patient with parasymphyseal fracture developing postoperative occlusal discrepancy.

And so, as regards postoperative occlusion in the current study no difference was reported between both groups and this is in agreement with Agrawal et al (27) who reported that no malocclusion was noted in both conventional and $3 \mathrm{D}$ miniplates groups. Also Melek et al (36) reported that at the fourth postoperative week, all patients of both groups had satisfactory occlusion.

In this study, a sensory deficit was related to the injury in $20 \%$ of the observed cases (a total of 4 cases out of 20 ), two patients from group (A) and two patients from group (B), with no incidence of postoperative sensory disturbance in both groups. This is in agreement with another study on 3D plates was done by Guimond et al (26), who also found that the main cause of sensory deficit in mandibular angle fractures was the trauma itself.

In the current study, the nerve function recovered within the first 3 months after surgery and this is in agreement with Agrawal et al (27) who reported that they did not face any mental nerve paresthesia in both groups, but in their opinion it is difficult to place a 3D plate near the mental foramen and it needs skill, time and patience. Also Melek et al (36) reported five cases with preoperative / post injury inferior alveolar nerve sensory disturbance who showed gradual improvement till the third month postoperatively.

In this study, pain intensity was significantly decreased in all cases of both groups across the follow up period and this is in agreement with Agarwal et al (27) who reported that a statistical significant difference was not found in the clinical parameters such as pain and swelling. Also Melek et al (36) showed that the postoperative clinical manifestations like pain and edema have resolved within the normal range of time in both groups and the findings were comparable between the two groups and within reasonable limits. Most propably adequate stabilization of the fracture segments that doesn't allow them to move apart eliminates the pain at the fracture site.

In this study, maximum mouth opening was significantly increased in all cases of both groups across the follow up period and this was in agreement with Melek et al (36) who reported that patients of both groups had improvement in maximal mouth opening by time until they resumed normal mouth opening by the third postoperative month that the opening between the upper and lower incisors easily accommodated three fingers $(35-40 \mathrm{~mm})$.

The present study showed a statistically non-significant difference regarding the mean bite force at the fractured side between the two groups. Yadav S et al (21) reported that at the third month it was found that there was no significant difference in the bite. Also Pepato et al (38) reported a good functional recovery achieved by the individuals who had a mandible angle fracture after 2 postoperative months. Melek et al study (36) showed a statistically significant difference regarding the mean bite force at the fractured side between the two groups at 2 and 4 weeks postoperatively with higher values reported in the $3 \mathrm{D}$ plate patients. While at 6 weeks postoperatively, the difference was nonsignificant.

However, reliability of the results is still questionable due to the considerable variation according to many other factors rather than the method of fixation like gender, age, state of dentition, malocclusion. For instance, during the post-pubertal period, maximum bite force increases at a greater rate in males than in females and thus becomes gender-related. Also, people with loss of periodontal tooth attachment have shown impaired sensory function resulting in reduced control of biting force in accordance to Van Spronsen et al (33), Shinogaya et al (34), Ikebe et al (35).

The results of this study showed that the increase in mean bone density was statistically significant in each of the groups from 45 days to 3 months postoperatively, consistent with the progress of fracture bone healing. The difference in mean bone density between the two groups was statistically non-significant mostly due to the fracture stability offered by the plates during the healing period. Melek et al reported (36) that the increase in mean bone density was statistically significant in each of the groups from 6 weeks to 3 months but the difference in mean bone density between the two groups was statistically non significant at 6 weeks postoperatively, however, it was significant at 3 months postoperatively, mostly due to the better fracture stability offered by the $3 \mathrm{D}$ plates during the healing period especially in displaced fractures.

\section{CONCLUSIONS}

From the results of this study we can conclude that:

1- 3D plate is effective in management of anterior mandibular fracture.

2- 3D plate provides the advantage of less operative time and less implant material in treatment of symphyseal and parasymphyseal fracture, with clinical results almost similar to those seen with conventional miniplate osteosynthesis.

3- It fulfills the treatment goals of adequate reduction, fixation and stabilization of fracture of mandible.

\section{CONFLICT OF INTERSET}

The authors declare that they have no conflicts of interest.

\section{REFERENCES}

1. Manson PN. Facial Injuries. In: McCarthy JG (ed). Plastic Surgery Vol. 2. Philadelphia: WB Saunders, 1990: 91678.

2. Anwar M, Iqbal T, Malik SA. A Study on the Surgical Management of Mandibular Fractures by Different Treatment Modalities. Pak J Plast Surg 2013; 2: 1-36.

3. Khan M. Management of Maxillofacial Trauma. AFID Dent Jr 1998; 10: 18-21.

4. Amanat N. Ananalysis of maxillofacial fractures in Aga Khan University Hospital. Pakistan J Surg 1993; 9: 128-32.

5. Mezitis M, Zachariades N, Rallis G. Anaudit of mandibular fractures treated by intermaxillary fixation, intraosseous wiring and compression plating. Br J Oral Maxillofac Surg 1996; 34: 293-7. 
6. Jaques B, Richter M, Arza A. Treatment of mandibular fractures with rigid osteosynthesis using AO system. J Oral Maxillofac Surg 1997; 55: 1402-7.

7. Sadhwani BS, Anchlia S. Conventional $2.0 \mathrm{~mm}$ miniplates versus 3-D plates in mandibular fractures. Ann Maxillofac Surg 2013; 3: 154-9.

8. Luhr HG. Vitallium Luhr systems for reconstructive surgery of the facial skeleton. Otolaryngol Clin North AM 1987; 20: 573-606.

9. Farmand M, Dupoirieux L. The value of 3-dimensional plates in maxillofacial surgery. Rev Stomatol Chir Maxillofac 1992; 93: 353-7.

10. Harada K, Watanabe M, Ohkura K, Enomoto S. Measure of bite force and occlusal contact area before and after bilateral sagittal split ramus osteotomy of the mandible using a new pressure-sensitive device: a preliminary report. J Oral Maxillofac Surg 2000; 58: 370-3.

11. SPI: Sensor Product Inc. [Internet] New Jersey. 2008. Available at: www.sensorprod.com/pressurex.php.

12. Shaaban AA. Clinical assessment of the bite force recovery in mandibular fracture patients following treatment with the two common treatment modalities. Master thesis, Faculty of Dentistry, Alexandria University 2002. 39-43.

13. Al-Bishri A, Barghash Z, Rosenquist J, Sunzel B. Neurosensory disturbance after sagittal split and intraoral vertical ramus osteotomy: as reported in questionnaires and patient's records. Int J Oral Maxillofac Surg 2005; 34: 247 51.

14. Chang JD, Bird SR, Bohidar NR, King T. Analgesic efficacy of rofecoxib compared with codeine/acetaminophen using a model of acute dental pain. Oral Surg Oral Med Oral Pathol Oral Radiol Endod 2005; 100: E74-80.

15. Jain MK, Manjunath KS, Bhagwan BK, Shah DK. Comparison of 3-Dimensional and Standard Miniplate Fixation in the Management of Mandibular Fractures. J Oral Maxillofac Surg 2010; 68: 1568-72.

16. Kotz S, Balakrishnan N, Read CB, Vidakovic B. Encyclopedia of statistical sciences. $2^{\text {nd }}$ ed. Hoboken, N.J.: Wiley-Interscience, 2006.

17. Kirkpatrick LA, Feeney BC. A simple guide to IBM SPSS statistics for version 20.0. Student ed. Belmont, Calif.: Wadsworth, Cengage Learning, 2013.

18. Champy M, Loddè JP, Schmitt R, Jaeqer JH, Muster D. Mandibular osteosynthesis by miniature screwed plates via a buccal approach. J Maxillofac Surg 1978; 6: 14-21.

19. Kumar BP, Kumar J, Mohan AP, Venkatesh V, Kumar HR. Three Dimensional Stainless Steel Plate versus Stainless Steel Miniplate in Mandibular Parasymphysis Fracture. J Bio Innov 2012; 1: 19-32.

20. Khalifa ME, El Hawary HE, Hussein MM. Titanium Three Dimensional Miniplate versus Conventional Titanium Miniplate in Anterior Mandibular Fracture. Life Science J. 2012; 9: 1006-10.

21. Yadav S, Agarwal A, Singh S, Kumar S, Anand KR, Chhabra V. 3-D locking titanium miniplates in management of mandibular fracture; A prospective 64-67 clinical study. J Dent Specialities 2015; 3: 64-7.

22. Farmand $M$. The 3D plating in maxillofacial surgery. J Oral Maxillofac Surg 1993; 51: 166-7.

23. Wittenberg JM, Smith BR, Trigg DD. Treatment of mandibular angle fractures with 3-D titanium miniplates. J Oral Maxillofac Surg 1994; 52: 106.
24. Hughes PJ. 3D plate versus the lag screw technique for treatment of fractures of anterior mandible. J Oral Maxillofac Surg 2000; 58: 23.

25. Zix J, Lieger O, Lizuka T. Use of straight and curved 3Dimensional titanium miniplates for fracture fixation at the mandibular angle. J Oral Maxillofacial Surg 2007; 65: 1758-63.

26. Guimond C, Johnson JV, Marchena JM. Fixation of mandibular angle fractures with a $2.0 \mathrm{~mm} 3$-dimensional curved angle strut plate. J Oral Maxillofac Surg 2005; 63: 20914.

27. Agarwal M, Meena B, Gupta DK, Tiwari AD, Jakhar SK. A Prospective Randomized Clinical Trial Comparing 3D and Standard Miniplates in Treatment of Mandibular Symphysis and Parasymphysis Fractures. J Maxillofac Oral Surg 2014; 13: 79-83.

28. Al-Moraissi EA, Ellis E. Surgical management of anterior mandibular fractures: a systematic review and metaanalysis. J Oral Maxillofac Surg 2014; 72: 2507.

29. Feledy J, Caterson EJ, Steger S, Stal S, Hollier L. Treatment of mandibular angle fractures with a matrix miniplate. A preliminary report. Plast Reconstr Surg 2004; 114: 1711.

30. Kawai T, Murakami S, Hiranuma H, Sakuda M. Radiographic changes during bone healing after mandibular fractures. Br. J Oral Maxillofac Surg 1997; 35: 312-8.

31. Smith WP. Delayed miniplate osteosynthesis for mandibular fractures. Br J Oral Maxillofac Surg 1991; 29: 73-6.

32. Regalo SC, Santos CM, Vitti M, Regalo CA, de Vasconcelos PB, Mesteiner W Jr, et al. Evaluation of molar and incisor bite force in indigenous compared with white population in Brazil. Arch Oral Biol 2008; 53: 282-6.

33. Van Spronsen PH, Weijs WA, Valk J, Prahl-Andersen B, van Ginkel FC. Comparison of jaw-muscle bite-force crosssections obtained by means of magnetic resonance imaging and high-resolution CT scanning. J Dent Res 1989; 68: 1765-70.

34. Shinogaya T, Bakke M, Thomsen CE, Vilmann A, Sodeyama A, Matsumoto M. Effects of ethnicity, gender and age on clenching force and load distribution. Clin Oral Investig 2001; 5: 63-8.

35. Ikebe K, Nokubi T, Morii K, Kashiwagi J, Furuya M. Association of bite force with aging and occlusal support in older adults. J Dent 2005; 33: 131-7.

36. Melek LN, El Mahallawy AS, Sharara AA, Ezz El Din A, Nour El-Din AHM. Evaluation of the 3-Dimensional Threadlock plate in the management of mandibular angle fractures. Ph.D. Thesis. Department of Oral and Maxillofacial Surgery, Faculty of Dentistry, Alexandria University. 2014.

37. Parmar S, Meanat S, Raghani M, Kapadia T. Three dimensional miniplates rigid fi xation in fracture mandible. J Maxillofac Oral Surg 2007; 6: 14.

38. Pepato AO, Palinkas M, Regalo SC, de Medeiros EH, de Vasconcelos PB, Sverzut CE, et al. Effect of surgical treatment of mandibular fracture: electromyographic analysis, bite force, and mandibular mobility. J Craniofac Surg 2014; 25: 1714-20. 